\title{
REPRESENTAÇÕES DE SAÚDE-DOENÇA DE UM GRUPO DE MULHERES RESIDENTES EM BAIRROS DA PERIFERIA DE BELO HORIZONTE (1994-1996)*
}

\section{HEALTH-SICKNESS REPRESENTATIONS OF A GROUP OF WOMEN FROM THE OUTSKIRTS OF BELO HORIZONTE (1994-1996)}

\author{
Clara J. Marques Andrade ${ }^{1}$ \\ Helena Paixão ${ }^{2}$ \\ Celina Modena ${ }^{3}$ \\ Antonio Maria Claret Torres ${ }^{4}$
}

ANDRADE, C. J. M.; PAIXÃO H.; MODENA, Á.; TORRES, A. M. C. Representações de Saúde-Doença de um Grupo de Mulheres Residentes em Bairros da Periferia de Belo Horizonte (1994/1996). Rev. Bras. de Cresc. e Desenv. Hum., S. Paulo, 7 (1), 1997.

Resumo: Este trabalho é resultado de uma pesquisa de campo, qualitativa, realizada nos bairros Solimões e Conjunto Jardim Felicidade, na região metropolitana de Belo Horizonte, com o objetivo de identificar as representações do processo saúde-doença de um grupo de mulheres residentes nos mesmos. Para sua execução optou-se por realizar a observação participante, entrevistas semi-estruturades e análise de conteúdo das entrevistas, segundo metodologia proposta por BARDIN, 1977), TRIVIÑOS 1987) e MINAYO (1993). As entrevistas foram realizadas no período de novembro de 1994 à julho de 1995 com trinta mulheres com idades entre 18 e 40 anos, todas com filhos de 0 a 5 anos. As entrevistas tiveram uma duração média de 60 minutos. Através da análise de conteúdo das entrevistas chegou-se às categorias de representação do processo saúde-doença. A doença é representada como incapacidade funcional e utilitária do corpo. A saúde, além de ser representada como o oposto da doença, ou seja, a capacidade funcional e utilitária do corpo, possui ainda outras representações, tais como: um modo de vida saudável, assistência médica de qualidade e, ainda, equilíbrio e harmonia nas relações com a natureza, com Deus. Este estudo evidencia que estas representações estão estreitamente relacionadas com as alternativas terapêuticas utilizadas pelos moradores. Tais alternativas, representadas por medicina científica, medicina caseira, automedicação, benzeção, curandeirismo e cura religiosa são buscadas de acordo com as concepções do processo saúde-doença.

Palavras-chave: representações sociais, processo saúde-doença, concepção de saúde-doença.

* Dissertação apresentada ao curso de mestrado em Epidcmiologia da Escola de Veterinária da UFMG. em março de 1996, cujo título foi "Representações de Saúde-Doença e Alternadvas Terapêuticas em Bairros da Periferia de Belo Horizonte (1994- 1996).

1 Mestre em Epidemiologia pela Escola de Veterinária da Universidade Federal de Minas Gernis. Profa. Assistente do Depto. de enfermagem Materno-Inlantil e Saúde Pública da Escola de enfermagem da UFMG.

2 Dra. em Sociologia pela École des Haustes Etudes em Sciences Sociales - Paris - França, Profa. Adjunta do Depto. de Odontologia Social c Preventiva da Escola de Odontologia da UFMG.

3 Dra. em Epidemiologia pela Universidade Federal do Rio de Janeiro e Profa. Adjunta do Depto. de Medicina Veterinária Preventiva da Escola de Veterinária da UFMG.

4 Mestre em Epidemiologia pela Escoia de Veterinária da UFMG. Prof. Assistente do Depto. de Medicina Veterinária Preventiva da Escola Vceterinária da UFMG. End.: Rua Catanduvas, 550, Renascença, Belo Horizonte - MG - CEP 30130-600. 


\section{INTRODUÇÃO}

O presente trabalho é fruto de uma pesquisa de campo, desenvolvida junto a um grupo de mulheres, moradoras dos bairros Solimões e Conjunto Jardim Felicidade, na região metropolitana de Belo Horizonte, MG, que surgiu da minha atuação enquanto enfermeira e docente no serviço de saúde local.

O presente estudo tem como objetivo identificar as representações de saúde doença de um grupo de mulheres que dedicam grande parte do seu tempo ao cuidado com a saúde dos filhos.

\subsection{Representações Sociais}

As representações sociais podem ser entendidas como categorias de pensamento que uma sociedade utiliza para elaborar e expressar sua realidade. Durkheim foi o primeiro a usar o termo representações coletivas, definidas como categorias de pensamento, que surgem ligadas aos fatos sociais, sendo elas próprias fatos sociais, podendo ser observadas e interpretadas. Para esse autor as representações sociais são um conjunto de fenômenos reais, que se comportam de forma específica, podendo exercer sobre os indivíduos uma espécie de coerção para atuar em determinado sentido. A religião, a moral, as categorias de espaço, tempo e de personalidade são exemplos de categorias que Durkheim destaca como "representações sociais históricas” (MINAYO, 1993).

Segundo SPINK (1989), o termo representação social foi resgatado por Moscovici, no interior da psicologia social, a partir da idéia de representação coletiva trabalhada por Durkheim.

Para MOSCOVICI (1969), a representação social pode ser definida como "um sistema de valores, de noções e de práticas, tendo uma dupla vocação. Primeiramente, instaurar uma ordem que possibilite aos indivíduos orientar-se no meio social e material e dominá-lo. Em seguida, assegurar a comunicação entre os membros de uma comunidade, propondo-lhes um código para nomear e classificar, de maneira unívoca, as partes de seu mundo, de sua história individual ou coletiva.” (p. 11). Este mesmo autor afirma que "toda representação emerge da nossa necessidade de transformar o que é estranho em algo familiar.” (p. 11).

A observação e a análise da linguagem do senso comum constituem formas privilegiadas de se apreender as representações sociais. Não sendo necessariamente conscientes, estas perpassam a sociedade reproduzindo-se e modificando-se a partir das estruturas e das relações sociais. As representações sociais constituem uma mistura das idéias da classe dominante, das camadas populares e das correntes filosóficas presentes na socie- dade, expressando as contradições existentes no plano das relações sociais de produção. Neste sentido contêm elementos da dominação, do conformismo e da resistência. (MINAYO, 1993).

As representações sociais, entendidas como senso comum, visão de mundo e idéias que os sujeitos possuem sobre a realidade, vêm atravessando a história e as mais diferentes correntes de pensamento sobre o social, constituindo importante campo de pesquisa nas Ciências Sociais (MINAYO, 1993). Neste aspecto, as representações sociais do fenômeno saúde-doença constituem importante material de estudo para se apreender como os sujeitos sociais vivenciam o processo de adoecer e de buscar alternativas de cura, informando também sobre a organização da sociedade e das relações sociais presentes.

\subsection{Representações de Saúde e Doença}

A representação social de saúde-doença manifesto, de forma específica, as concepções da sociedade que, através do discurso sobre a saúde, a doença e o corpo, deixa transparecer a coerência ou as contradições de sua visão de mundo e de sua organização social (LÉVI-STRAUSS, 1974). As ciências sociais possibilitaram ver o corpo que adoece e morre, dentro de uma ordem de significações mais abrangentes. O que aponta para o fato de a linguagem da doença ser uma linguagem que remete sempre à sociedade e as reações sociais.

Enquanto fenômeno social, a saúde-doença tem um esquema interno de explicações, tendo como referencial a visão dos especialistas (mágicos, rezadores, curandeiros e médicos) e o senso comum que expressa a experiência cotidiana (MINAYO, 1993).

Do ponto de vista individual, pode-se afirmar que o fenômeno saúde-doença ocorre em quatro dimensões. A primeira delas é estar doente e significa apresentar, no corpo e nas suas funções, alterações por causa da doença. A segunda é sentir-se doente, ou seja, perceber as modificações no próprio organismo. A terceira é identificar a doença, utilizando para isso os conhecimentos de época. E, por último, a quarta dimensão que é poder estar doente, sendo que a doença muitas vezes é negada até o limite do possível, para que se possa cumprir as obrigações das quais depende a existência cotidiana e a sobrevivência (BERLINGUER, 1988).

O indivíduo caracteriza-se como "sádio" ou "doente" não apenas pelas manifestações que percebe no seu corpo mas, para dar legitimidade à sua condição, busca sempre os especialistas da cura, presentes em cada sociedade. São os especialistas (mágicos, rezadores, curandeiros e mé- 
dicos) que legitimam a doença e a saúde dos indivíduos.

Fatores endógenos e exógenos estão presentes nas explicações sobre a causalidade do fenômeno saúde-doença, tanto entre os povos primitivos quanto na sociedade moderna. Os fatores endógenos são considerados do ponto de vista médico clínico e analisados através dos processos biológicos. Os fatores exógenos são pensados a partir da sociedade, ou seja, do desequilíbrio nas relações dos grupos sociais (MINAYO, 1993).

A concepção exógena da doença está ligada à sociedade, que é entendida como opressora, agressiva, pouco saudável. Tal concepção, presente entre os primitivos, considerava que as doenças eram causadas por divindades, feiticeiros, mágicos. No mundo moderno, as causas exógenas são atribuídas ao "modo de vida". HERZLICH (1991) caracteriza como modo de vida "o quadro espacial e temporal no qual o indivíduo vive e suas características (densidade de população e atmosfera), o ritmo de vida (horário e estímulos), assim como os reflexos em certos comportamentos cotidianos: alimentação, atividades, descanso, sono", (p. 26). Nesta concepção exógena da doença, o meio ambiente e a sociedade são causadores de doenças e desequilíbrio. O indivíduo, que se identifica com a saúde, é vítima de um mundo "malsão", urbano, moderno e opressor.

A concepção endógena da doença num primeiro momento, não revela o seu vínculo com o social, desde que, em primeira instância, é o indivíduo que adoece e morre. Mas esta concepção é socialmente construída, uma vez que as atribuições a desígnios divinos, de fatalidade ou desordem remetem à desobediência ou transgressão de normas coletivas, transcendendo o estado ogânico e o corpo individual (MINAYO, 1993).

A representação de saúde-doença, baseada na idéia do corpo como instrumento de trabalho, elaborada pela classe dominante (profissionais médicos) é reveladora das contradições presentes na sociedade. A noção de donça como incapacidade para trabalhar está relacionada com a economia, com a produção e reprodução econômica. Tal representação mostra uma realidade onde o corpo é o único gerador de bens. O corpo doente significa inatividade social, trazendo para a experiência cotidiana a miséria, a fome e o desespero, mostrando ao indivíduo que seu corpo é "sua fonte de subsistência e sua única fonte de reprodução” (MINAYO,1989, p.82 e 1993, p. 185). A negação da doença, até o limite do possível, é a estratégia que garante a sobrevivência (BERLINGUER,1988, p.45).

\section{METODOLOGIA}

\subsection{Seleção das Mulheres da Pesquisa}

A pesquisa foi situada nos bairros Solimões e Conjunto Jardim Felicidade. Localizados na Regional Norte do município de Belo Horizonte (M G), estes bairros possuíam uma população de migrantes de cidades do interior de Minas Gerais e estados do nordeste do Brasil.

Foi realizada com 30 mulheres, mães de crianças inscritas nas ações de Controle de Crescimento e Desenvolvimento do Programa de Atenção à Saúde da Criança do Ministério da Saúde, no posto de saúde local. Como critério de definição para a seleção do conjunto de mulheres a serem entrevistadas considerou-se que este grupo seria relevante para a realização das entrevistas e observação, uma vez que todas as mulheres entrevistadas, com idade entre 18 e 40 anos, tinham filhos menores de 5 anos, sendo que o número de filhos das mesmas oscilava entre 2 e 8 filhos.

Em relação a este grupo, - as seguintes características foram comuns:

- procedência: todas as entrevistadas migraram do interior do Estado. Algumas há mais de dez anos, outras mais recentemente;

- profissão e renda familiar: as profissões predominantes no grupo entrevistado eram faxineira, diarista, empregada doméstica, costureira e cozinheira, o que dava uma remuneração mensal de 1 a 2 salários mínimos. Cerca de dez entrevistadas não trabalhavam fora, e o sustento da família era realizado pelo marido;

- escolaridade: todas as entrevistadas sabiam ler e escrever, mas a escolaridade do grupo não ultrapassava a $8^{\mathrm{a}}$ série. Cerca de $80 \%$ das mulheres possuíam $1^{\circ}$ grau incompleto, tendo cursado apenas até a $3^{\text {a }}$ série.

\subsection{Coleta e Análise dos Dados}

Como se tratava de uma pesquisa qualitativa tendo como tema as representações de saúde e doença, os instrumentos de coleta e análise dos dados utilizados foram aqueles recomendados por autores como BARDIN (1977), TRTVINOS (1987) e MINAYO (1993).

As entrevistas semi-estruturadas tiveram uma duração de 30 a 90 minutos cada, sendo que a duração média do total das entrevistas foi de 60 minutos. Para tal utilizou-se um guia de entrevista, que permitiu dar um direcionamento à conversa, sem interferir na linha de raciocínio da informante. As perguntas não foram elaboradas anteriormente, surgindo a partir das informações dadas pelas mulheres, quando era introduzido o tema das entrevistas, ou seja, a saúde, a doença e as estratégias por elas utilizadas. As entrevistas 
foram realizadas no período de novembro de 1994 a Fevereiro de 1995, nas casas das mulheres.

A observação participante, nesta pesquisa, teve início durante o desenvolvimento de meu trabalho enquanto docente e enfermeira, no posto de saúde do bairro e ao participar das atividades desenvolvidas pelos moradores dos bairros desde o ano de 1986.

No caso desta pesquisa, a amostragem de tempo considerada foi de quatro anos, período em que foi mantido um diário de campo com anotações de comportamentos, atitudes, falas e hábitos, relacionados à saúde e à doença dos moradores do bairro Solimões e Conjunto Jardim Felicidade. Neste diário de campo constavam ainda algumas reflexões realizadas durante a observação e participação nas atividades desenvolvidas nos bairros. Estas se referiam a questões teóricometodológicas e a aspectos que precisavam ser melhor indagados e observados.

A pré-análise dos dados teve início durante a transcrição e leitura das entrevistas. possibilitando pouco a pouco que a leitura se tornasse mais precisa no sentido de identificar as categorias de análise.

Na etapa de descrição analitica procedeuse ao estudo aprofundado das entrevistas. A partir das informações das entrevistadas sobre a saúde, a doença e as condutas em cada caso foram elaboradas as categorias de análise que serão apresentadas e discutidas no item 4. Efetuar a transcrição de vinte entrevistas do total de trinta c duas contribuiu significativamente para a realização dessa etapa uma vez que tal fato possibilitou um conhecimento mais aprofuundado das informações.

A partir da análise das categorias elaboradas na etapa de descrição analítica buscou-se estabelecer relações entre estas categorias, o referencial teórico e a realidade observada, aprofundando a reflexão sobre o processo saúde-cloença e as estratégias utilizadas por esta população.

\section{RLSULTADOS E DISCUSSÃO}

Antes da apresentac,ão das categorias de análise é necessário comentar três aspectos observados com o desenvolvimento da pesquisa.

O primeiro aspecto é que ao falar sobre a saúde e a doença. as entrevistadas informam de duas maneiras. Em relação à saúde, suas informações são mais reticentes, sendo que às vezes ficam em silêncio ou dizem que não sabem responder. Algumas expressões como: "saúde é tudo". "saúde vale mais que o dinheiro”, "saúde é o maior bem que Deus deu prá gente”. aparecem nos seus discursos. que mostram a saúde como um bem vago, abstrato, idealizado. aparentemente distante da sua experiência cotidiana.

Em contrapartida, quando interrogadas sobre a doença, fornecem muitas informações, com riqueza de detalhes, demonstrando, assim, um conhecimento considerável em relação aos sintomas e aos cuidados que se deve ter em cada caso. A doença torna-se um desafio a enfrentar cotidianamente, o que a torna mais conhecida, sendo por isso mesmo, mais fácil falar sobre ela.

Estc aspecto reflete uma situação onde a saúde e a doença são vivenciados em graus variados. onde a saúde, mesmo sendo "tudo", nem sempre está presente. Falam de uma saúde "vivida" que faz parte da sua experiência cotidiana, onde conseguem manter a capacidade funcional e utilitária do corpo. em contraposição com uma saúde "idcalizada" que - "é tudo", que "é estar bem em todos os sentidos". Nesse contexto, a definição da saúde não fica clara. ela existe na medida em que se pode usar o corpo. Mas o corpo que se usa (talvez saudável) denuncia outro estado, a doença, que mesmo negada, demonstra para o corpo a sua existência.

O segundo aspecto a ser comentado é a facilidade das mulheres para informarem sobre a situação de saúde-doença dos outros (filhos. maridos. parentes. vizinhos), em detrimento da sua. Talvez pela dificuldade em falar diretamente sobre si mesmas, durante uma entrevista gravada, numa situação de pesquisa. Ou ainda, pelo fato de que todas as mulhercs entrevistadas têm filhos na faixa etária de 0 a 5 anos. $\mathrm{O}$ cuidado com a saúde dos filhos nesta faixa etária demanda um tempo considerável. fazendo com que as mulheres prestem mais atenção aos filhos do quc a si mesmas.

O terceiro e último aspecto a ser considerado é em relação à força criadora das mulheres. Durante a realização desta pesquisa (entrevistas e observação participante) pôde-se observar vários momentos onde as mulheres são colocadas em "situações limite", diante de problemas cotidianos com sua saúde, dos filhos, vizinhos e difículdades de acesso ao serviço de saúde. Nessas situações apresentam uma força criadora, que dá a elas a capacidade de resolver os problemas encontrando caminhos e soluções aparentemente inexistentes. Principalmente em "situações limite”, representadas pela doença e/ou pela morte. É possível afirmar que a todo momento, as mulheres das camadas populares reinventam novas formas de enfrentar as dificuldades que são urna rotina diária. 


\subsection{Concepção de Saúde e Doença}

\subsubsection{Saúde como capacidade funcional e utilitária do corpo}

A categoria de representação de saúde presente em $100 \%$ das entrevistas refere-se à saúde como um valor que garante aos indivíduos a sua sobrevivência e o desempenho de seu papel, principalmente no âmbito familiar. Expressões como "saúde é tudo", "é melhor ter saúde do que ter dinheiro", "sem saúde a gente não é nada," entre outras, são freqüentes no discurso das entrevistadas. Considerada como o bem maior que possuem, a saúde é representada como: alegria disposição para o trabalho, estar bem em todos os sentidos, demonstrando, assim, que ter saúde significa conseguir usar bem o corpo. Para isso é necessário boa alimentação, higiene e repouso, considerados como os fatores de saúde. A saúde está ligada à idéia de força, que permite ao individuo usar bem o corpo. Esta força é garantida e estimulada pela alimentação.

Esta representação de saúde como "disposição para a vida em geral”, tendo como fator principal a alimentação, que aparece em todas as entrevistas, é encontrada também nas pesquisas realizadas por LOYOLA (1984) e QUEIROZ (1991).

Ao falarem sobre a saúde sempre recorrem a situações de doença, numa tentativa de definir melhor como é "ter saúde". A doença é representada como fraqueza, abatimento, prostração indicando, nesse caso, o inverso, ou seja, a incapacidade de usar o corpo para exercer as atividades habituais. A doença dos adultos é percebida subitamente, como alguma coisa que acontece de repente causando uma ruptura no estado normal (a saúde).

O estudo de BOLTANSKI (1979) traz conclusões semelhantes. Este autor afirma que, para os membros das classes populares, a doença se manifesta brutalmente porque eles não percebem os sinais precursores, ou mesmo se recusam a percebê-los, isto porque não prestam voluntariamente atenção a seus corpos, usando-os principalmente como instrumento, ou seja, subordinam seus corpos às funções sociais que desempenham. Enfim, a doença "constitui para eles aquilo que interrompe o tempo, que corta o desenrolar normal da vida e oblitera o futuro inteiro". (BOLTANSKI, 1979, p. 166).

Mesmo que o corpo dê sinais antes do aparecimento abrupto da doença, esses sinais ou não são percebidos ou, se percebidos, são negados como uma forma de se continuar utilizando um "corpo sádio". Todas as entrevistas apresentam concepções semelhantes às dos depoimentos a seguir:
"Eu num ligava. Eu não percebia. Isso é que, a correria do dia-a-dia ô Clara as pessoas num percebe que tá duente não, que isso aconteceu comigo. Cênão percebe que tá duente. É onde acontece com as pessoas, internô ontem morreu hoje cabô de interná e morreu, nem deu tempo de interná. A culpa fica no médico, mas a culpa é da gente mesmo. A correria do dia a dia, a falta de condição e é isso que acontece... Eu num tinha responsabilidade com minha saúde não, trabaIhava, trabalhava, trabalhava trabalhava e num preocupava com nada não"

(E 10P 19 - dona de casa, 39 anos)

O fato de esperarem o máximo possível para procurarem um atendimento de saúde demonstra que a necessidade de garantir a sobrevivência dificulta o abandono do emprego e/ou das tarefas domésticas. Aqui se evidencia que as relações que se estabelecem no trabalho, as condiçõ̃es de trabalho a que os indivíduos estão submetidos dificultam, ou até mesmo impedem, que os mesmos prestem atenção a seus corpos. Pelos depoimentos acima percebe-se a "necessidade" que os membros das camadas populares têm de esquecer os sinais dados por seus corpos. Em contrapartida, quando percebem abruptamente a doença se sentem culpados. A contradição presente aqui é que, se por um lado, as exigências cotidianas obrigam a esse distanciamento do corpo, por outro, são essas mesmas exigências que cobram do indivíduo um corpo-máquina que funcione bem. Assim, quando percebem que esse corpo não corresponde ao esperado, ou seja, quando se dão conta que estão doentes, os indivíduos se culpam por não terem percebido antes os sinais dados por seus corpos.

Tal sentimento tende a ser reforçado quando os membros das classes populares buscam a assistência médica oficial, uma vez que, aí, as doenças provocadas pelas condições de vida e de trabalho são tratadas como questão individual, perdem o seu caráter social e são tranformadas em "descuido', "ignorancia” e "culpa". Dentro dessa contradição os membros das classes populares criam incessantemente maneiras de unificar num mesmo corpo, as condições de vida e as exigências sociais a que estão expostos.

Este fato é particularmente verdadeiro no caso dos homens. Pelos depoimentos das mulheres, percebe-se, através de expressões como: "ele tem uma saúde de ferro", "não procura médico prá qualquer duencinha não"; "trabalha direto e não sente nada"; "só tem problema de pressão, mas tá com saúde", "só procura médico em último caso", que os homens demoram mais a procurar assistência em caso de doenças. 
Os homens são vistos como mais fortes, no sentido de adoecerem menos, fato que pode estar ligado a valores da cultura brasileira, onde dar demasiada atenção ao corpo e demonstrar fraqueza é considerado uma atitude de mulher. As pesquisas de BOLTANSKI (1979), com as classes populares francesas, e LOYOLA (1984) com os moradores e agentes terapêuticos de Nova Iguaçu, na Baixada Fluminense, confirmam tal perspectiva. É interessante observar que tal comportamento em relação à doença é freqüente na sociedade, que não a brasileira, conforme evidencia o estudo de Boltanski, mencionado acima

Esse autor afirma que os membros das camadas populares reprovam os indivíduos que “passam a vida no médico", valorizando aqueles que demontram resistência à dor e que em muitos casos esperam que o mal passe por si mesmo, só procurando assistência médica quando o mal tenha atingido uma intensidade tal que os impeça de fazer uso normal do corpo.

Quando interrogadas sobre quem adoece mais, se o homem ou a mulher, elas informam que a mulher adoece mais porque tem mais preocupação, mais atividades (principalmente quando trabalha fora de casa). O depoimento dessa entrevistada fala da percepção da doença, relacionada com a condição de ser mulher:

"Eu acho que é as mulheres, que os homens é assim mais tranqüilo, né. Pensa menos, trabalha menos, e a mulher não, é 24 horas no ar, né. Ela tem que tá ligada, seja em casa ou no serviço. Chega em casa tem que dá banho no minino, tem que fazê janta. O home não, ele chega, toma o banho dele, ou vai pro boteco bebê ou deita na cama pré-descansa, né. E a gente não, a gente tem que tá ali, enquanto a gente não acaba não tem condições de deitá. Acho que a gente mais adoece por causa disso. Os home num tem filho, é só a mulher que tem".

(E12 p22 - faxineira -38 anos)

Esses depoimentos, quer se refiram aos homens ou às mulheres, contêm uma representação de doença como incapacidade para o trabalho, que é negada até o limite possível no sentido de se continuar garantindo o sustento da família.

Esta representação da doença remete sempre a alternativas de cura que atuem dentro de uma lógica sintomática, ou seja tratando de suprimir os sintomas da doença repondo a força de trabalho individual. Tais alternativas são representadas pela prática médica (serviço oficial de saúde), a automedicação ou o uso de chás caseiros, que podem ser usados simultaneamente ou não, conforme o caso.

A nega,cão da doença e a demora em procurar o serviço de saúde, observada em relação aos adultos, não ocorre quando se trata de doenças infantis. As crianças são consideradas "mais sensíveis", "frágeis e incapazes de falar o que estão sentindo”, sendo necessário dar mais atenção e cuidados à sua saúde, porque elas não conseguem avaliar a intensidade dos sintomas.

A saúde, nesse caso, é representada como alegria, disposição para brincar, alimentar e dormir bem. A criança doente, ao contrário, "'fica enjoadinha”, "quieta pelos cantos", "não brinca, não come nem dorme bem”, "fica esmurecida", “procura logo a cama”. Neste caso, a representação de saúde-doença fala de um uso funcional do corpo, sendo que os sinais são percebidos tão logo se instalem. Todas as mulheres entrevistadas demonstraram uma grande preocupação com a saúde dos filhos, relatando constantemente os cuidados e o tempo que dedicam a essa tarefa.

Percebe-se uma preocupação das mães em tratar as verminoses das crianças. Este tratamento é feito com recursos caseiros (principalmente através de chás e simpatias), benzeção e uso de medicamentos industrializados. Estes medicamentos são usados, em muitos casos, sem que se faça antes um exame parasitológico. São adquiridos nas farmácias, sem receita médica.

A preocupação com o tratamento e controle em casos de verminoses é comum em relação às crianças. $\mathrm{O}$ mesmo não acontece quando se trata dos adultos. Várias mulheres informam que é importante tratar das crianças porque elas precisam “desenvolver bem.” O adulto “já está formado” e não sofre as mesmas conseqüências. Apenas dois tipos de vermes são considerados perigosos também para os adultos, a "xistosa" e a "solitária", porque "podem subir prá cabeça provocando acesso e desmaio".

O tratamento da verminose é realizado semestralmente como uma forma de prevenção. Entretanto, as mulheres têm conhecimento de que problemas como: inexistência de rede de esgoto, o lixo espalhado pelas ruas, o córrego sem canalização e o abastecimento deficiente de água são fatores de transmissão da doença e precisam ser solucionados.

Em relação às verminoses percebe-se um comportamento contraditório. Não são consideradas doenças, no entanto, constituem objeto de preocupação e cuidados constantes das mães, relacionados aos filhos menores de 5 anos. Algumas delas como a esquistossomose e a teníase são temidas, não porque signifiquem doença, mas porque podem provocar convulsões ("acesso"), desmaios ou até mesmo a morte. A doença, neste caso, é caracterizada somente quando os sinais e sintomas presentes impliquem numa dificuldade de exercer as atividades costumeiras. 
O mesmo se observa em relação a vários estados mórbidos, relatados pelas mulheres, que mesmo representando risco para sua saúde, não são considerados doenças porque não incapacitam os individuos de exercerem suas atividades. Como exemplo este depoimento:

"Ele lá com quase 90 anos, ele viaja prá Caldas Novas, vai pré Aparecida do Norte. Cê precisa ver a saúde que ele tem, sabe. Apesar de ter problema de coração, ele tem angina, mas tem aquela saúde. De onde vem aquela saúde? Do modo de vida dele".

(E1 P31 - dona de casa 30 anos)

A representação de saúde-doença como capacidade-incapacidade funcional e utilitária do corpo remete à idéia de espaços distintos para se vivenciar cada um dos dois estados. Estados mórbidos, que do ponto de vista médico são considerados "doenças", não são vivenciados como tal pelos indivíduos, conforme pode-se observar pelos depoimentos acima. É neste sentido que se pode falar de uma "saude vivenciada" e uma "saúde idealizada.”

A saúde vivenciada pelos indivíduos perinite que eles se considerem saudáveis (negando ou não a doença) exercendo suas atividades costumeiras. Tal concepção está presente em todas as entrevistas, onde há relatos de vários estados mórbidos, freqüentes entre a população, que não são percebidos como doenças.

O estudo de ROUX (1994) sobre as doenças endêmicas em determinados grupos sociais apresenta-se nesta mesma perspectiva. Afirma este autor que mesmo que causem danos graves, algumas doenças não são consideradas como tal, desde que determinado grupo social esteja adaptado a elas.

Em contrapartida, a saúde idealizada pelos indivíduos aparece na forma de expressões como "saúde é tudo," "é o maior bem que Deus deu prá gente.” As categorias de representação de saúde como um modo de vida saudável e saúde como equilíbrio remetem sempre a essa visão idealizada de saúde.

\subsubsection{Saúde como um modo de vida saudável}

A segunda categoria de representação de saúde identificada é a de saúde como um modo de vida saudável. Esse "modo de vida saudável" deve ser buscado pelo indivíduo, cotidianamente, através de determinados cuidados com seu corpo: como alimentação adequada, higiene, sono, repouso e gosto pela vida. Esses cuidados são considerados fatores imprescindíveis para se ter uma boa saúde.
Em relação à alimentação, fator de saúde mencionado em todas as entrevistas, percebe-se uma grande preocupação por parte das mulheres em garantir uma aliinentação de qualidade para a família, principalmente para as crianças.

O conceito de uma boa alimentação é construído a partir das informações obtidas com os profissionais de saúde, bem como daquelas veiculadas pela televisão inescladas aos costumes alimentares tradicionais. A alimentação de boa qualidade, para elas, inclui arroz, feijão, verduras e frutas frescas, carnes e ovos, bem como "dano-ninhos", iogurtes e outros alimentos industrializados.

Entretanto, apesar de valorizarem a importância dessa alimentação saudável as mulheres falam da dificuldade de se conseguir dar à família o que elas consideram uma alimentação adequada. Não falam diretamente de que se constitui a sua alimentação e sim do que seria ideal. Segundo MINAYO (1989), em geral as pessoas sentem vergonha em verbalizar sobre sua alimentação, porque inferiorizam como "culpa pessoal” o fato de não ter o suficiente para alimentar os filhos, o fato de comer mal e de receber salários irrisórios. Depoiinentos como o descrito abaixo são freqüentes, mostrando o valor atribuído à alimentação como fator de saúde:

"Prá mantê e prá conservá, o que mantém a gente em pé é a alimentação, né. E se a pessoa se alimenta bem, tem variedade de coisa em casa, de vez em quando pelo menos, porque geralmente muitas pessoa assim, num tem condições de ter uma carne, legumes, isso ajuda muito na alimentação, na saúde. Porque o que faz a gente ficá em pé é o alimento."

(E11 P5 - dona de casa - 20 anos)

Outro fator de saúde mencionado em todas as entrevistas é a higiene valorizada tanto quanto a alimentação. Quando as mulheres falam sobre a higiene apontam dois aspectos. O primeiro é o cuidado que têm dentro de suas casas, no preparo dos alimentos, na limpeza das vasilhas, das roupas e dos seus corpos. Pela observação percebe-se o valor que atribuem à higiene como fator de saúde. As casas, com raríssimas exceções, são limpas e bem cuidadas, nas cozinhas vasilhas brilhando, chão limpo, o que contrasta com a situação observada nas ruas. O segundo aspecto é em relação ao que acontece fora de suas casas, com acúmulo de lixo nas ruas, esgotos arrebentados e muita poeira. Numa mesma fala mostram a higiene como fator de saúde e que têm conhecimento da importância e dos limites do que fazem.

"O Clara! o que causa as doença nas pessoas mesmo com todos os cuidados que a gente tem é a falta de higiene, é o que nós vivemos aqui no Conjunto. Porque não adianta eu lê todos os cuidados e tê um esgoto a céu aberto na rua. Quer 
dizer esse esgoto seca, vem a soleira esse pó contaminado vai invadi a sua casa, pousa nas coisa. A responsável pela doença é a sujeira das ruas."

(E10 P13 - dona de casa - 39 anos).

A representação de saúde como um modo de vida saudável é veiculada todos os dias pelo sistema oficial de saúde e pelos meios de comunicação. E uma representação elaborada pela classe dominante, repassada para as camadas populares que a reinterpretam dentro do seu contexto. Ao falarem de um "modo de vida saudável," que vêem como ideal, as mulheres falam da sua experiência existencial que dificulta o acesso a este "modo de vida”. O que se observa é que as mulheres, através de códigos próprios, criam alternativas adequando essa representação elaborada pela classe dominante às suas condições de vida, buscando construir cotidianamente um "modo de vida saudável".

O seu discurso fala das dificuldades de se colocar na mesa alimentos de boa qualidade e de suas estratégias para garantir uma alimentação razoável para a família. Fala do valor que percebem em uma boa higiene e da experiência de se conviver cotidianamente com a situação inversa, que é preciso mudar e que no entanto não depende só delas. Percebem limites na sua ação no sentido de resolver problemas básicos relacionados com o bairro onde moram.

A representação de saúde como "um modo de vida saudável” remete a uma representação da sociedade como "agressiva e opressora," que determina um "modo de vida" causador de doenças no indivíduo. No caso específico dessa pesquisa, a fala das entrevistadas mostra que "o modo de vida” a que estão submetidas é considerado causador de doenças. Sua fala remete às relaçoes que estabelecem no trabalho, que remetem à desvalorização, à submissão e ao desgaste de seus corpos, retratando o modo de vida a que estão submetidas as mulheres das camadas populares.

"Trabaiá não é ruim, eu acho ruim naquele serviço que eu trabaio só porque as Irmã, elas num desgruda da gente. Não assim o serviço, eu adoro trabaiá, prá mim se elas me deixasse trabaiá, mas acontece que elas humilha a gente, elas xinga a gente...

A gente trabaia lá que a gente precisa, mas trabaia revoltado. Elas joga muita coisa na cara da gente. Eu guardo tudo prá mim, ai começa, o coração deve ficá fraco, os nervo também né, aí chega em casa tem pobrema tamém né, junta tudo ...

Eu num gosto de respondê os outros.

Aí eu esqueci uma chave aqui em casa e vim buscá. Aí ela me xingô, me xingô tanto, que eu pro resto aquilo foi abafano assim, e eu cheguei aqui em casa tava passano mal".

(E12 P13-12-11 - faxineira - 38 anos)

\subsubsection{Saúde como assistência médica de qualidade}

A terceira categoria de representação de saúde elaborada é a de saúde como assistência médica de qualidade. Remete à representação de saúde como um bem coletivo, ultrapassando o campo médico e chegando ao campo das reivindicações sociais.

A avaliação que fazem do serviço e dos profissionais é subjetiva, baseada na experiência adquirida ao utilizarem tais serviços, que podem ser os postos de saúde locais e/ou hospitais e ambulatórios localizados em outros bairros da cidade.

O profissional de saúde, especialmente o médico, é avaliado a partir de critérios subjetivos, como atenção, carinho e cuidado que dedica aos clientes. Os estudos de BOLTANSKI (1979), LOYOLA (1984) e QUEIROZ (1991) apresentam constatações semelhantes. Se o profissional não apresenta tais atributos, nem sempre a sua recomendação é aceita e seguida. Nesse sentido, é a relação que conseguem estabelecer com o profissional de saúde que determina o quanto confiam nas suas prescrições. Estabelecem uma distinção entre "saber muito" e "ser bom médico", conforme o depoimento de uma das entrevistadas em relação a um médico que atende no posto de saúde local:

"Eu falo e é verdade, às vezes o remédio do médico num vale de nada e o chazinho da vovó com carinho, que num tinha nada a vê com aquilo, cura. É o carinho, é o afeto, isso é fundamental. Tem um médico aqui no posto, um pediatra, eu num sei se ele continua aí, ele pode ser muito bom, pode ter sido o melhor aluno da faculdade, como médico ninguém tem fé nele. Eles simplesmente não vão dá aquele remédio, vão procurá outro médico, sahe. A primeira vez que eu levei lá, o minino tava muito cansadinho, com pneumonia, ele prá começá ele te mata de estado de nervo, dá a impressão que o minino tá morreno. Ele não fala um A com você, ele escreve tudo, anota aquilo, num sei o que tanto escreve sem falá um A com você. Aí cê quase morre, a receita já tá pronta quando ele começa conversá com a gente. Ele pode ser um excelente médico, mas não $e$. Ele num te fala nada, quando ele chega abri a boca ce já deu dor de cabeça, já endureceu, está num estuado de nervo, ele já escreveu o relatório do que vai saí e do que vai entrá, sabe. Eu acho assim. um bom atendimento, o afeto e a atenção é a base de tudo".

(E10 P26 - dona de casa - 39 anos)

Os depoimentos evidenciam que as entrevistadas não seguem as prescrições médicas quando não confiam no profissional. Como estrátégia para conseguir resolver seu problema procuram 
outro profissional e/ou outro serviço de saúde. Não questionam diretainente o profissional no qual não confiam, o que aparentemente significa conformismo e submissão; entretanto, ao não seguirem as prescrições e buscarem outras alternativas e estratégias, resistem a uma prática médica autoritária e pouco confiável.

Ao representarem a saúde como assistêneia médica de qualidade falam do seu inverso, falam de uma assistência precária e desqualificada, de profissionais pouco acessíveis e não confiáveis e das estratégias que desenvolvem para conseguir tal assistência. Percebe-se que as estratégias são criadas individualmente, de acordo com as necessidades de cada caso, apesar de serem semelhantes as dificuldades sentidas.

São resolvidas individualmente, com a ajuda de parentes, amigos, vizinhos, o que mostra a solidariedade existente entre eles. Não existe, entretanto, uma forma organizada de discussão e tentativa de solucionar as dificuldades relacionadas ao serviço de saúde local.

\subsubsection{Saúde como equilíbrio e harmonia com Deus}

A quarta categoria elaborada é a da representação de saúde como equilíbrio, harmonia com Deus, com a natureza. Essa representação está centrada numa visão mais totalizante do fenômeno saúde-doença, uma vez que o ser humano é percebido como corpo/alma ou matéria/espírito. A saúde vista como harmonia, equilíbrio, remete à idéia de doença como desequilíbrio, desordem no corpo/alma, nas relações afetivas e nas condições de vida e de trabalho.

É dentro dessa concepção que as entrevistadas classificam as doenças em "materiais” e “espirituais”. Segundo sua classificação, as doenças materiais apresentam sinais no corpo, sendo causadas por micróbios, falta de higiene, poeira, ou seja, causas físicas. Necessitam de um tratamento que atue sobre essas causas. $\mathrm{O}$ tratamento pode ser através do recurso caseiro, da auto medicação e/ou do médico.

As doenças espirituais em determinado momento passam a apresentar sinais no corpo, afetando o individuo e desorganizando sua vida. As causas apontadas dessas doenças são: castigo divino, provação de Deus a um fiel, chamado para a vida cristã, o diabo, energias negativas mau olhado, inveja, feitiço.

As entrevistadas informam que, em casos de doenças espirituais, o recurso médico não resolve, sendo necessário procurar um outro tipo de "especialista" que entenda desses assuntos. Esse especialista pode ser um benzedor, um curandeiro, um pastor, um pai de santo, dependen- do da via religiosa da pessoa doente. Esta pesquisa identificou que os especialistas procurados pelos moradores são os pastores das igrejas pentecostais, as benzedeiras e os curandeiros.

Em muitos casos as doenças são classificadas em “materiais” ou “espirituais,” de acordo com a resposta a um determinado tratamento, ou seja, a doença só é classificada após o tratamento apresentar resultados positivos. Nestas situações são procuradas, simultaneamente, várias alternativas terapêuticas, contribuindo para a classificação das doenças. Esta classificação possui limites muito tênues, conforme observado por LOYOLA (1984), e uma mesma doença pode ser incluída na categoria de "material” ou "espiritual," dependendo da resposta obtida com o tratamento.

Em relação ao tratamento das doenças espirituais, o que fica patente em todas as falas é que o recurso médico não é eficaz quando se trata de doença espiritual. O depoimento abaixo demonstra com clareza essa concepção:

"Quando é essas coisa assim que é de benzedô, o remédo de médico não vale nada... Aí o benzedô benze, a criança fica boa então a gente sabe que ela tá com quebranto, mau olhado, qualquer coisa. Quebranto, mau olhado, cobrero é só com benzedô, o médico não resolve isso não"

(E 12 P 16 - faxineira - 38 anos`

Ao representarem o fenômeno saúde doença como equilíbrio-desequilíbrio, as entrevistadas reafirmam a legitimidade de outros especialistas da cura que não os médicos. O desequilíbrio, a desordem que se instaura no corpo e/ou nas relações cotidianas são resolvidos no nível simbólico, de uma forma mágica, integradora e eficaz, como pode ser observado no depoimento abaixo:

"Nossa, graças a Deus! A gente tinha uma vida, sabe? Ele saia fim de semana, voltava... não ia trabalhar sexta, só chegava sábado de madrugada. Era aquela confusão. Hoje não. Hoje graças a Deus eu posso dizer: hoje eu sou feliz. Porque felicidade não é dinheiro. Hoje eu sou feliz, graças a Deus. Tenho Deus na minha vida, tô na Igreja com as menina...

Porque lá o nosso Deus é o Deus do impossível, né? Quando o que é impossível pro homem, prá Deus tudo é possível. Mas há coisas que é permissão de Deus e há coisas que é a cura. Essa Mariana mesmo, Jesus curou ela de bronquite, foi cura mesmo, instantânea”.

(E24 P 12 - dona de casa - 28 anos)

\section{CONSIDERAÇÕES FINAIS}

As quatro categorias de representação do fenômeno saúde-doença elaboradas e discutidas 
anteriormente se encontram presentes, em graus variáveis, em todas as entrevistas. A representação da doença como incapacidade para o trabalho é a mais freqüente, aparecendo em 100\% das entrevistas, sustentam a visão do corpo como o único instrumento que garante a sobrevivência dos indivíduos. Outra representação, tambén freqüente em $80 \%$ das entrevistas, é a de saúde como assistência médica de qualidade, que remete ao campo dos direitos sociais e mostra as relações entre o serviço oficial de saúde e as camadas populares. A representação de saúde como equilíbrio, harmonia com Deus, presente em $40 \%$ das entrevistas, chama a atenção para o crescimento do movimento de cura divina entre as camadas populares no Brasil. A representação de saúde como um modo de vida saudável, 30\% das entrevistas, veiculada pela classe dominante reinterpretada pelas mulheres que adequam esse modo de vida às suas condições de existência. Essas representações foram apresentadas separadamente no sentido de facilitar a discussão das mesmas, entretanto, o que se observa ao analisar o material das entrevistas é que uma mesma pessoa possui as várias representações da saúde e da doença.

São as representações do fenômeno saúde-doença discutidas anteriormente que ajudan a detenninar quais alternativas de cura serão utilizadas pela população, conferindo-lhes um determinado grau de legitimidade de acordo com o seu uso e difusão entre a população.

\begin{abstract}
This paper is a result of a field research based on qualitative data, carried out with a group of women living at Solimões and Conjunto Jardim Felicidade neighborhoods, in the metropolitan arca of Belo Horizonte - MG, with the goal of identifying their representations ofthe health-sickness process. The data were collected througlh participative observation, semi-structured interviews and analyses of the interviews, according to the methodology proposed by BARDIN (1977), TRIVINOS (1987) and MINAYO (1993). The interviews, that lastedapproximately 60 minutes, were conducted from November, 1994 to July, 1995 with thirty women varying from 18 to 40 years of age, all of them with children between 0 and 5 years old. The analyses of the content of the interviews provided the categories of representation of the healtl^l-sickness process. Sickness is represented as funcional and utilitarian incapacity of the body. Health, besides beh^lg represented as the contrary of sickness, in other words, a functional and utilitarian body, has yet many other representations, such as: a healthy lifestyle, qualified medical assistance, and also balanced and harmonious relations with nature and God. This study shows that these representations are stricky related to the therapeutic alternatives adopted in the neighborhoods. Such alternatives, represented by scientific medicine, home medich^le, selfmedication, "blessings”, "witch doctors”, and miraculous cures are sought according to the conceptions of the health-sickness process.
\end{abstract}

Key-words: social representations, health-sickness process,health-sickness conception.

\section{REFERÊNCIAS BIBLIOGRÁFICAS}

BARDIN, L. Análise de conteúdo. Lisboa, Edições 70, 1977. p. 225.

BASTOS, E. L.; TELLES, P. R.; CASTIL110, E., et al. A epidemia de AIOS no Brasil. ln: MINAYO, M. G. Os muitos Brasis. Saúde e população na década de 80. São Paulo. Rio de Janeiro, Hucitec-Abrasco, 1995 p. 145-258.

BERLINGUER, G. A doença. São Paulo, Hucitec/ CEBES. 1988.p.150.

BOLTANSKY, L. As classes sociais e o corpo. Rio de Janeiro, Grall, 1979 p. 191.

BORGES, S. M. N., ATIÊ, E. Vida de mulher: estratégias de sobrevivência no cotidiano. In: COSTA, N. R., RAMOS, C. L.; MINAYO, C.; STOTZ, E. N. Demandas populares, políticas públicas e saúde. Petrópolis, Vozes, 1989. V.2, p.165-184.
HERZLICIH, C. A problemática da representação social e sua utilidade no campo da doença. PHYSIS - Rev. Saúde Col. 1(2): 23-35, 1991.

KOIFMAN, S. Incidência de câncer no Brasil. In: MINAYO, M. C. Os muitos Brasis. Saúde e população na década de 80. São Paulo, Hucitec, 1975, p. 143-176.

LAPLANTINE, F. Antropologia da doença. São Paulo, Martins Fontes, 1991, p. 274.

LÉVI-STRAUSS, C. Introdução à Obra de Marcel Mauss. In: MAUSS, M. Sociologia e antropologia. São Paulo, EPU/EDUSI', 1974. v. 2.

LOYOLA, M. A. A medicina popular. In: GUTMARÃES, R. Saúde e medicina no Brasil: contribuição para um debate. Rio de Janeiro, Graal, 1978. v.3, p. 225-236. 
LOYOLA, M. A. Médicos e curandeiros, conflito social e saúde. São Paulo, Difel, 1984. p. 198.

MAUSS, M. Antropologia. São Paulo, Atica, 1979.

MELI O, S. L. Trabalho e sobrevivência. Mulheres do campo e da periferia de São Paulo. São Paulo, Ática, 1988. p. 192.

MINAYO, C. Na dor do corpo, o grito da vida. In: COSTA, N., RAMOS, C. L., MINAYO, C., STOTZ, E. N. Demandas populares, políticas públicas e saúde. Petrópolis, Vozes, 1989. v. 2, p. 75-101.

MINAYO, M. C. O desafio do conhecimento: pesquisa qualitativa em saude. $2^{\mathrm{a}}$ ed. São Paulo, Hucitec-Abrasco, 1993. p. 262.

MONTERO, P. Da doença à desordem, a magia na Umbanda. Rio de Janeiro, Graal, 1985. p. 274 .

MOSCOVICI, S. Prefácio. In: HERZILICII, C. Santé et maladie; analyse dome représentation sociale. Paris, La Haye. Mouton, 1969.

PAIXÃO II. Saúde e Doença: um estudo de representação social. Anais Cent. Est. Cur. Odont., Belo Horizonte, v. 23, no 1 e 2, p. 917. 1986.

POSSAS C. Epidemiologia e sociedade. Heterogeneidade estrutural e saúde no Brasil. São Paulo, Hucitec. 1989. p. 271.
QUEIROZ, M. S. O Paradigma mecanicista da medicina ocidental moderna: uma perspectiva antropológica. Rev. Saúde Pública, 20(4): 309-317, 1986.

QUEIROZ, M. C. Representações de saúde e doença; Agentes de cura e pacientes no contexto do SUDS. Campinas, Unicamp, 1991, p. 138.

ROUX, G. I. La prevención de comportamientos de riesgo y la promoción de estilos de vida saludable en el desarrollo de la salud. Educ. Med. Salud, 28(2): 23-33, 1994.

SABROZA. P. et. al. Doenças transmissíveis: ainda com desafio. In: MINAYO, M. G. Os muitos Brasis. Saúde e população na década de 80. São Paulo. Rio de Janeiro, HucitecAbrasco, 1995. p 177-244.

SONTAG, S. A doença como metáfora. Rio de janeiro, Graal, 1984, p. 108.

SONTAG, S. A Aids e suas metáforas. São Paulo, Companhia das Letras, í989. p. 111.

SPINK, M. I. As representações sociais e suas aplicações em pesquisa na área da saúde. São Paulo, PUC, 1989, p.25.

TRIVINOS, A. N. S. Introdução à pesquisa em ciencias sociais: A pesquisa qualitativa em educação. São Paulo, Ática, 1987.

Recehido em 09/06/97 Aprovado em 20/09/97 